\title{
Translinguajamento: pensando entre línguas a partir de práticas e metadiscursos de docentes indígenas em formação superior
}

\section{Translanguaging: thinking between language based on practices and metadiscourses of indigenous teachers in higher education}

Denise Pimenta de Oliveira Universidade Federal de Goiás Goiânia, Goiás, Brasil.

André Marques do Nascimento Universidade Federal de Goiás Goiânia, Goiás, Brasil.

\begin{abstract}
Resumo: O objetivo deste trabalho é estabelecer a genealogia epistemológica do conceito de translinguajamento, a partir de pressupostos teóricos do campo dos estudos decoloniais, e compreendê-lo com base em práticas comunicativas e metadiscursos de docentes indígenas em formação superior específica na Universidade Federal de Goiás (UFG). O translinguajamento é apresentado como uma alternativa para problematizar os essencialismos decorrentes da invenção das línguas (MAKONI; PENNYCOOK, 2007) - e, consequentemente, das nações e de outros construtos - e para compreender as práticas comunicativas contemporâneas. Pretendemos mobilizar reflexões relacionadas a práticas híbridas de linguagem, que rompam com a ideologia do monolinguajamento colonial e nacional e considerem a possibilidade de pensar entre línguas, na fronteira, conforme sugere Mignolo (2003), considerando o processo de globalização e os contextos locais e pensando a interculturalidade de forma crítica, marcada por processos de interação amplamente diversificados e profundamente afetados pela diferença colonial. Além disso, procuramos evidenciar e compreender como práticas e metadiscursos relacionados a essa ideia de translinguajamento se manifestam em um contexto de formação de docentes indígenas no curso de Licenciatura em Educação Intercultural da Universidade Federal de Goiás, a partir de dados orais e escritos gerados em sala de aula, em uma análise com direcionamento metodológico qualitativo e de cunho etnográfico. Considera-se o translinguajamento como uma alternativa para desinventar e reconstituir as línguas, questionando concepções fixas e totalizantes sobre linguagem, sobretudo em situações em que a complexidade social reconfigura os mapas linguísticos e exige novas perspectivas, como é o caso dos povos indígenas no Brasil. Para tanto, partimos da ideia de que o translinguajamento pode, inclusive, ser utilizado como uma estratégia de negociação nas relações interculturais, intrinsicamente constituídas na fluidez e no hibridismo, fundamentadas na mobilização de recursos pertencentes a repertórios linguísticos diversos, móveis e heterogêneos.
\end{abstract}

Palavras-chave: Translinguajamento. Interculturalidade. Povos indígenas.

Abstract: The objective of this paper is to establish the epistemological genealogy of the concept of translanguaging from theoretical assumptions in the field of decolonial studies and to understand it based on communicative practices and metadiscourses of indigenous teachers in higher education at Federal University of Goiás (UFG). Translanguaging is presented as an alternative to problematize the essentialisms arising from

* Mestranda no Programa de Pós-Graduação em Letras e Linguística da Universidade Federal de Goiás, Goiânia, Goiás, Brasil. Email: denisep.ol@gmail.com.

* Doutor em Linguística. Professor Adjunto no curso de Licenciatura em Educação Intercultural da Universidade Federal de Goiás, Goiânia, Goiás, Brasil. Email: marquesandre@yahoo.com.br. 
the invention of languages (MAKONI; PENNYCOOK, 2007) - and consequently from "nation" and other constructs - and to understand contemporary communicative practices. We intend to mobilize reflections related to hybrid language practices that break with the ideology of colonial and national monolingualism and consider the possibility of thinking between languages, of a border thinking, as Mignolo (2003) suggests, considering the process of globalization and local contexts and thinking about interculturality in a critical way, marked by processes of interaction widely diversified and profoundly affected by the colonial difference. In addition, we seek to evidence and understand how practices and metadiscourses related to this idea of translanguaging are manifested in a context of higher education of indigenous teachers in the undergraduate course of Intercultural Education at Federal University of Goiás, based on oral and written data generated in the classroom, in an analysis with qualitative and ethnographic methodological orientation. Translanguaging is considered as an alternative to disinvent and reconstitute languages, questioning fixed and totalizing conceptions about language, especially in situations in which social complexity reconfigures linguistic maps and demands new perspectives, as is the case of indigenous peoples in Brazil. Therefore, we start from the idea that translanguaging can even be used as a negotiation strategy in intercultural relations, intrinsically constituted in fluidity and hybridity, based on the mobilization of resources belonging to diverse, mobile and heterogeneous linguistic repertoires.

Keywords: Translanguaging. Interculturality. Indigenous people.

\section{O IMAGINÁRIO DO SISTEMA MUNDIAL COLONIAL/MODERNO E A INVENÇÃO DAS LÍNGUAS}

O "nascimento" da modernidade, ocorrido em 1492 com a invasão da América (DUSSEL, 1994) e sua constituição como novo continente, em um duplo movimento que constituía concomitantemente a ideia de Europa (QUIJANO, 2005), trouxe consigo a colonização do imaginário, que consistiu em uma repressão, “[...] sobretudo, sobre os modos de conhecer, de produzir conhecimento, de produzir perspectivas, imagens e sistemas de imagens, símbolos, modos de significação [...]" dos povos colonizados (QUIJANO, 1992, p. 13), um dos aspectos da colonialidade do saber/poder ${ }^{1}$. Constróise, assim, o que Mignolo (2003) denomina "imaginário do sistema mundial colonial/moderno", uma nova ordem geopolítica mundial que se configura a partir da "descoberta" da América e da consequente emergência de um novo circuito econômico e comercial.

$\mathrm{Na}$ fundação do imaginário colonial/moderno, está a hierarquização dos sujeitos colonizados com base em suas raças, consideradas inferiores em relação aos europeus, um aspecto biologizante usado como justificativa para exterminar ou subjugar os povos colonizados, em um processo de violência não apenas física, mas epistemológica. Subalternizam-se, assim, os corpos, as línguas, os conhecimentos, as epistemologias e as práticas desses sujeitos, situando-os em um passado longínquo dentro de uma trajetória temporal que insere a modernidade em que vive a Europa no extremo oposto, como se os colonizadores representassem o estágio mais evoluído da humanidade, em contraposição aos povos colonizados, situados no estágio mais primitivo e, por muito tempo. destituídos de humanidade.

Assim, a negação da contemporaneidade "tornou-se uma das estratégias mais poderosas para a colonialidade do poder e a subalternização das línguas, saberes e culturas" (MIGNOLO, 2003, p. 385), compondo o imaginário, inclusive na atualidade,

${ }^{1}$ Neste trabalho, são nossas todas as traduções das citações de obras em língua estrangeira. 
do que é ser índio a partir da associação desses povos a uma identidade pré-colonial, fixando identidades e desqualificando os sujeitos indígenas que não se enquadrem nessa idealização (NASCIMENTO, 2014). Esse tipo de essencialização é mais uma forma de opressão, parte da colonização do imaginário dos colonizados, um meio muito eficaz de "controle social e cultural, quando a repressão imediata deixou de ser constante e sistemática”. (QUIJANO, 1992, p. 13).

Nesse sentido, desenhava-se um projeto de governabilidade na constituição da colonialidade/modernidade, em um processo de hierarquização por meio do estabelecimento de prefigurações identitárias dos povos colonizados, fortemente baseadas em critérios etnolinguísticos, uma vez que a noção de língua constituiu e foi constituída pelas ideologias de essência nacional e racial, conforme argumentam Makoni e Pennycook (2007). Os autores defendem que "as línguas e as concepções de linguacidade [languageness] e metalinguagem que são usadas para concebê-las são invenções [...], como parte dos projetos cristãos/coloniais e nacionalistas em diferentes partes do mundo" (MAKONI; PENNYCOOK, 2007, p. 1). Dessa forma, a invenção das línguas tem papel fundamental na essencialização dos sujeitos, que passam a ter uma identidade fixa determinada, por exemplo, pela naturalização da tríade "um povo-um território-uma língua", reforçada por Herder no contexto do romantismo alemão, em uma ideologia nacionalista que se constrói sobre o ideal monolíngue.

Ser índio significa, dentro dessa lógica, falar uma língua indígena "legítima”. Quanto mais o sujeito se afasta desse modelo de identidade prefigurativo - utilizando recursos identificados como pertencentes de outras línguas, por exemplo -, menos ele corresponde à idealização desse construto. A ideologia monolíngue tem nitidamente um propósito dentro do projeto de governabilidade colonial/moderno, conforme enfatiza Nascimento (2017):

A autenticidade cultural, nela incluída uma identidade etnolinguística fixa, é o que, em tese, garantiria aos povos indígenas certos direitos, como o de terem legalmente reconhecidos os seus territórios tradicionais. $O$ discurso de autenticidade, ou inautenticidade, é, contudo, apropriado contingencialmente, a depender dos interesses político-econômicos supralocais, a despeito de toda a complexidade que constitui as dinâmicas interculturais contemporâneas que, inevitavelmente, impactam a existência dos povos indígenas. (NASCIMENTO, 2017, p. 5).

A ideia de monolinguismo se associa, por sua vez, à ideologia artefatual da língua, compreendida como

[...] uma ideologia especializada em que a diversidade desconcertante que caracteriza a língua real em contextos reais ("fala") pode ser reduzida a apenas um punhado de formas e regras que organizam as combinações de tais formas [...] que essas formas e regras são tudo o que há na língua, são "a língua” e ponto final. (BLOMMAERT, 2014, p. 71, grifos do autor).

Assim, a língua é vista como um sistema bem ordenado e delimitado (daí a possibilidade de enumerá-la e categorizá-la), de forma que determinados recursos e estruturas são estritamente atribuídos a uma língua específica, e não a outra, de modo que não se "confundem", compondo a identidade de sujeitos territorializados e 
etnolinguisticamente prefigurados. A língua como sistema abstrato, nomeado e "descrito" (em um processo não somente de descrição, mas de constituição performativa) passa a ser idealizada com base em noções de purismo e fixidez, as quais sustentam e são sustentadas pelo ideal monolíngue. Consideramos, portanto, que essas ideologias, intrinsecamente relacionadas, constituem ideologias modernas/coloniais de linguagem, ao passo que fundamentam os modos de controle e opressão na e pela língua de sujeitos cujas epistemologias e práticas - que tanto se diferem da cosmologia europeia - são subalternizadas.

\section{TRANSLINGUAJAMENTO: PENSANDO ENTRE LÍNGUAS NO ESPAÇO DA DIFERENÇA COLONIAL}

Todo o imaginário moderno/colonial descrito anteriormente e as ideologias modernas de linguagem, mais especificamente, desconsideram a dinamicidade intercultural das práticas comunicativas e a própria mobilidade dos povos indígenas, ainda mais impactada pelos processos recentes de globalização (WANG et al., 2014), bem como os contextos locais que se distanciam das noções universais modernas (NASCIMENTO, 2017). Essa é mais uma decorrência da invisibilização desses sujeitos e de suas práticas e epistemologias (nesse caso, relacionadas à linguagem), como um dos efeitos reais da invenção das línguas, um modo de negar as práticas comunicativas contemporâneas dos povos indígenas inseridos em uma "nação" na qual não cabem, na perspectiva da sociedade não indígena, senão como objetos relegados a um passado histórico e primitivo. Como principal consequência, a indianidade, vista principalmente a partirsua exterioridade, só se legitima se for constituída por uma língua indígena "pura". É ainda interessante perceber como perspectivas hegemônicas de estudos da linguagem no mundo ocidental perpetuam tais ideologias. Como argumenta Nascimento (2017),

[...] é possível compreender como as chamadas "línguas indígenas" têm sido objeto de análise sob duas principais perspectivas hegemônicas que compartilham a assunção da correlação inequívoca entre língua, cultura e território, e da fixidez, homogeneidade e estabilidade linguísticas. A primeira delas dedica-se à análise de características sistêmico-funcionais, sob diferentes abordagens teóricas e que tem como principais resultados descrições (não raro, chamadas de gramáticas) de partes de língua em suas dimensões fonético-fonológicas, morfossintáticas e, em menor escala, textuais ou discursivas. É, provavelmente, a perspectiva de maior impacto na produção acadêmica brasileira. Outra perspectiva de grande produtividade e que se vincula às áreas de educação em língua materna e dos direitos linguísticos, enquadra-se nos limites de uma sociolinguística tradicional, que busca apresentar a situação das línguas indígenas em contínuos classificatórios, cujos polos mais radicais vão da vitalidade funcional às situações de risco de extinção e morte, tendo como principal critério de classificação o número de falantes que utilizam essas línguas (metodologia que se funda, também, em invenções como a delimitação fixa e estável, portanto enumerável, das línguas e de seus falantes). Tarefa fundamental desta abordagem é, ainda, a compreensão dos fatores "externos" que expliquem as diferentes situações sociolinguísticas das comunidades indígenas que, no geral e apesar de toda a complexidade envolvida, desde esta perspectiva, compartilham o risco da perda ou substituição e do destino comum de serem vítimas da homogeneização sociocultural e linguística causada pelo contato, normalmente analisado desde categorias pautadas na ideologia do monolinguismo, aqui compreendida como um 
complexo de ideias, crenças e práticas por elas motivadas que assumem, como fundamento, "que as pessoas são intrinsecamente monolíngues, suas línguas são padrões (puros) e seus territórios limitados e sociolinguisticamente homogêneos" (BLOMMAERT, 2006, p. 518). (NASCIMENTO, 2017, p. 5-6)

Mignolo (2003, p. 30) sugere que os conhecimentos desses povos subjugados, os "saberes subalternos", desqualificados na estrutura da colonialidade do poder, sejam recolocados dentro de um pensamento liminar, o que significa "pensar nas e a partir das margens [...] como uma futura ruptura epistemológica". Para o autor, o pensamento liminar emerge das histórias locais, em oposição aos projetos globais disseminados pelo mundo por um único viés, e "situa-se nas fronteiras (interiores + exteriores) do sistema mundial colonial/moderno" (MIGNOLO, 2003, p. 126). O pensamento liminar somente pode ser construído a partir da diferença colonial, que consiste no

[...] espaço onde as histórias locais que estão inventando e implementando os projetos globais encontram aquelas histórias locais que os recebem; é o espaço onde os projetos globais são forçados a adaptar-se, integrar-se ou onde são adotados, rejeitados ou ignorados. A diferença colonial é, finalmente, o local ao mesmo tempo físico e imaginário onde atua a colonialidade do poder, no confronto de duas espécies de histórias locais visíveis em diferentes espaços e tempos do planeta. (MIGNOLO, 2003, p. 10).

Mignolo (2003) parte, então, da definição de languaging postulada por Becker (1988) (cf. GARCÍA; WEI, 2014), para explicar um processo que sempre está em curso, sendo criado e reconfigurado enquanto interagimos linguisticamente, e que seria mais condizente, em termos teórico-analíticos, com as experiências de vidas nas fronteiras do mundo moderno/colonial. Conforme Mignolo, o linguajamento consiste, assim, no "[...] ato de pensar e escrever entre línguas [...]”, constituído nas fissuras da diferença colonial ao passo que constitui uma maneira de "pensar entre línguas", deixando de enxergá-las como artefatos, "[...] em direção à ideia de que a fala e a escrita são estratégias para orientar e manipular os domínios sociais de interação [...]” (MIGNOLO, 2003, p. 309). Mignolo elabora a discussão em torno desse conceito, baseando-se em experiências e teorizações trazidas por pensadores situados geo e corpo-politicamente nas margens do sistema mundial moderno/colonial, como José María Arguedas (1962), Michele Cliff (1995), Gloria Anzaldúa (1987), Frantz Fanon (1952) e Alfred Arteaga (1994), entre tantos outros, o que representa uma forma de "teorizar línguas dentro de estruturas sociais de dominação", desafiando a "ideologia monolingual e a hermenêutica monotópica da modernidade e do nacionalismo" (MIGNOLO, 2003, p. 311), a partir de uma cosmovisão não eurocentrada, como forma de atribuir a visibilidade a epistemologias apagadas e subalternizadas. Buscam-se, assim, “[...] modelos e genealogias além das línguas coloniais do período moderno [...] e de suas bases autoritárias [...] em 'nossas' inserções locais no sistema global" (MIGNOLO, 2003, p. 375).

$\mathrm{Na}$ busca por genealogias de conhecimento que emergem no espaço da diferença colonial, destacamos aqui as reflexões de Mutua Mehinaku (2010), que, a partir de suas vivências como sujeito indígena do Alto Xingu contemporâneo, elabora o conceito de tetsualï, palavra que "pode ser traduzida como 'misturado', como uma mistura de cores 
no colorido de alguma coisa", para explicar práticas híbridas envolvendo pessoas e línguas, a "mistura de etnias na história de vida de uma pessoa" (MEHINAKU, 2010, p. 1). Para o autor, o encontro e a integração de diferentes povos e culturas no Alto Xingu promovem a mistura, ressaltando que "cada povo interpreta e denomina conceitos, valores e rituais comuns de acordo com sua própria língua" (MEHINAKU, 2010, p. 144), o que reafirma a ideia de que a língua representa, mais que um mero código, um modo de viver e enxergar o mundo, constituindo e sendo constituída pelos processos sociais e culturais. Mutua Mehinaku defende que "o Alto Xingu é tetsualï" (2014, p. 1), em um processo de formações multiculturais e plurilíngues ocorridas ao longo dos últimos mil anos. Segundo ele, mais recentemente, a chegada dos não indígenas tornou

[...] ainda mais complexos os comportamentos, pensamentos e modos de viver dos altoxinguanos. O conceito de tetsualü, quando falamos da língua da nova geração, ganhou outro sentido e valor pelo fato do Português ser uma ponte de comunicação entre povos distintos. [...] É a nova geração que é o agente das novas tecnologias dos Brancos - tecnologias do olhar e da palavra. (MEHINAKU, 2014, p. 194).

Mignolo (2003) argumenta que o processo de globalização, ao qual Mutua Mehinaku também faz referência, promoveu a recolocação de línguas e culturas, por meio da fragmentação de línguas imperiais em práticas que surgem em diversos locais do mundo, e a reemergência de línguas minoritárias, ambas estimuladas tanto pelos movimentos migratórios quanto pelas configurações nacionais contemporâneas, a partir dos processos de descolonização e do fortalecimento de movimentos sociais. Ele propõe que o bilinguajamento pode ser entendido como "o viver-entre-línguas", considerando o linguajamento como "o momento no qual uma 'língua viva' (como diz Anzaldúa) se descreve como um estilo de vida ('um modo de vivir') na interseção de duas (ou mais) línguas" (MIGNOLO, 2003, p. 358). Percebe-se, assim, que o bi/plurilinguajamento não se trata da mera manifestação de habilidades linguísticas de duas línguas, mas de uma ação política que envolve vários repertórios identificados como pertencentes a línguas diversas, constituída na diferença colonial como forma de desafiar a colonialidade do poder, constituindo uma nova epistemologia.

Partindo dessas noções e da ideia de que a transculturação identifica o lócus dos fenômenos e processos de recolocação de linguagens no mundo globalizado, consideramos que os conceitos de bi/plurilinguajamento de Mignolo (2003) podem ser entendidos também, de forma mais ampla, como translinguajamento. Aproxima-se dessas discussões o conceito de translinguajamento postulado por García e Li Wei (2014), uma abordagem que considera as práticas de linguagem "não como dois sistemas autônomos de linguagem, como tem sido tradicionalmente o caso, mas como um repertório linguístico com características que têm sido socialmente construídas" (GARCÍA; WEI, 2014, p. 2). Para os autores, o translinguajamento consiste em

[...] ações de linguagem que ordenam um processo político de transformação social e da subjetividade que resiste às assimetrias do poder que a linguagem e outros códigos produtores de sentido, associados a uma ou outra ideologia nacionalista, produzem. (GARCÍA; WEI, 2014, p. 43). 
Nessa perspectiva, a ideia de linguajamento de Mignolo (2003) transcende o construto "nação", diante dos borrões que vêm se constituindo em suas fronteiras internas e externas e das consequentes práticas comunicativas híbridas e identidades cambiantes que delas emergem. Os elos entre língua, território e identidade, uma das principais crenças do imaginário colonial/moderno (MIGNOLO, 2003), têm sido desatados pelos movimentos dos corpos e dos conhecimentos dos sujeitos no mundo e pela retomada dos contextos locais. Nesse sentido, é preciso encarar o translinguajamento não somente como uma prática e um objeto de estudo, mas como uma epistemologia, como uma forma de pensar entre línguas, a partir das margens, conforme propõe Mignolo (2003).

\section{CONTEXTO DA PESQUISA E ANÁLISE COMO PRÁTICA DE ENTEXTUALIZAÇÃO}

Partindo da ideia de translinguajamento como prática e epistemologia inserida no espaço da diferença colonial, conforme desenvolvida na seção anterior, procuramos compreender como essa noção emerge das práticas e dos metadiscursos de docentes indígenas em formação superior específica, como forma de posicionar o pensamento fronteiriço desses sujeitos, historicamente marginalizados, no centro das discussões sobre linguagem.

Primeiramente, é necessário esclarecer o contexto desta pesquisa, de direcionamento metodológico qualitativo de cunho etnográfico e que se centra na análise de dados discursivos orais e escritos gerados em contextos de sala de aula do curso de Educação Intercultural, da Universidade Federal de Goiás (UFG), que tem como principal objetivo

[...] formar e habilitar professores indígenas [...] para lecionar nas escolas do ensino fundamental e ensino médio, com vistas a atender à demanda das comunidades indígenas no que toca à formação superior de seus professores. (UFG, 2006, p. 12).

O curso de Educação Intercultural da UFG prevê uma matriz de formação básica e matrizes específicas: Ciências da Cultura, Ciências da Natureza e Ciências da Linguagem, pensadas de maneira a contemplar as noções de interculturalidade, transdisciplinaridade, diversidade e sustentabilidade, as quais baseiam toda a concepção do curso, e compostas por temas contextuais e estudos complementares (UFG, 2006). Para a geração dos dados desta pesquisa, acompanhamos o tema contextual "Português como primeira e segunda língua”, parte da matriz curricular específica de Ciências da Linguagem, oferecido aos estudantes (ingressos do ano de 2014) em etapa realizada em julho de 2016 em Goiânia, no Núcleo de Formação Superior Indígena Takinahakỹ, na Universidade Federal de Goiás.

Destacamos a necessidade de atentarmos para um aspecto importante da pesquisa: sua realização no espaço da universidade, evidenciando a presença de sujeitos indígenas de diversas etnias dentro da academia, contexto que 
[...] pressupõe, ou deveria pressupor, o re(encontro) dialógico crítico e igualitário com ontologias e epistemologias de diferentes matrizes culturais, historicamente apagadas, silenciadas e deslegitimadas por uma geopolítica do poder (NASCIMENTO, 2014, p. 104).

Além disso, é importante pensar como o acesso desses sujeitos à educação superior e como o fato de serem pessoas que, em geral, transitam com frequência nas zonas de contato interculturais os posicionam nesse contexto e impactam na concepção e produção de seus metadiscursos sobre língua. É preciso levar em conta, por exemplo, que esses sujeitos somente puderam ocupar esse espaço porque se apropriaram em algum nível dos recursos da língua portuguesa, requisito no modelo atual para o estabelecimento das relações interculturais dentro da universidade, espaço onde as práticas comunicativas em língua portuguesa são predominantes.

Outro aspecto da geração de dados que precisa ser considerado é sua realização em contexto de sala de aula, em temas contextuais concernentes à reflexão sobre linguagem e ensino de línguas em cenários interculturais. Ressalte-se, ainda, que o professor responsável pelos temas contextuais e estudos complementares orienta a pesquisa aqui proposta e compartilha dos mesmos posicionamentos teóricos adotados, de modo que as atividades observadas, nas quais os dados foram gerados, foram de muitos modos estimuladas, de forma interessada, pelo docente. Isso delimita de modo ainda mais específico o contexto de produção das falas e dos textos escritos, na medida em que envolvem

[...] práticas socioculturais voltadas para a reflexão metalinguística e metacomunicativa, pois favorecem manifestações de consciência metapragmática por parte dos interactantes, que se mostram mais sensíveis às interpretações/avaliações de suas próprias ações (verbais e não verbais) e das de seus interlocutores no curso da interação; e fazem comentários sobre a natureza, as contingências e limitações das ações em curso; sobre os alinhamentos e desalinhamentos dessas ações com outras precedentes e/ou simultâneas; e também sobre as relações sociais que se estabelecem. (SIGNORINI, 2008, p. 122).

A partir disso, adotamos uma concepção crítica de contexto, tendo como aspiração problematizar "a sociedade através dessa janela aberta pelo discurso", encarando a linguagem (e as ideologias da linguagem) "ela mesma um objeto de desigualdade e hegemonia" (BLOMMAERT, 2008, p. 114).

Ainda em relação aos dados aqui trazidos, é fundamental esclarecer que admitimos que sua própria geração e análise - incluindo a presença dos pesquisadores, a gravação dos encontros em sala de aula e a posterior transcrição das produções orais - não se resumem à coleta e descrição, mas propriamente constitui o material da pesquisa, pois esses processos pressupõem uma perturbação no andamento dos contextos de produção, além de, inevitavelmente, refletirem escolhas dos pesquisadores, sobretudo em relação à seleção e interpretação dos fenômenos.

Assim, assumimos as transcrições dos dados como "atividade analítica plena", "produtos analíticos pautados por propósitos analíticos específicos" (GARCEZ, 2002, p. 84; 85). Neste trabalho, realizamos um recorte de trechos das produções escritas e orais dos docentes indígenas que pudessem ser caracterizados como metadiscursos, ou seja, 
enunciados local e historicamente situados que orientam em si mesmos a compreensão de formas linguísticas e seus usos, que assumem funções metapragmáticas, ou seja, funções "tanto de descrever e avaliar quanto de condicionar e orientar os usos da língua" (SIGNORINI, 2008, p. 117).

No mesmo sentido, enxergamos "a análise como prática de entextualização", como parte da trajetória do texto (BLOMMAERT, 2008, p. 98), uma vez que recontextualizamos metadiscursivamente as produções orais e escritas dos docentes indígenas com o propósito de evidenciar as ideologias de linguagem emergentes, realizando nós mesmos, como analistas, um exercício metapragmático. Dessa forma, se extrai

O texto do contexto, posicionando-o em outro contexto e adicionando qualificações metapragmáticas a ele, de forma a especificar as condições pelas quais os textos deveriam ser compreendidos, o que eles querem dizer e o que significam, e assim por diante. (BLOMMAERT, 2008, p. 99).

A ideia é tomar "a intertextualidade e a entextualização em conjunto", a fim de localizar os enunciados metadiscursivos (situados localmente) em um quadro histórico mais amplo, "o que nos permite entender os eventos discursivos individuais como elementos eminentemente sociais, culturais e políticos" (BLOMMAERT, 2005, p. 48).

É fundamental destacar que, no caso desta pesquisa, os metadiscursos orais e escritos de sujeitos indígenas foram enunciados em um importante espaço de produção de conhecimento, a universidade, o que desperta para a necessidade de que suas vozes sejam ouvidas dentro da academia e ecoem nos estudos sobre a língua, por tanto tempo monopólio de estudiosos e especialistas que ignoraram e invisibilizaram as concepções linguísticas dos falantes e seu poder de agenciamento sobre sua própria língua.

Assim, concebemos os metadiscursos indígenas não como meros "dados a serem analisados, mas como instâncias de diálogo intercultural e, portanto, interepistêmico" (NASCIMENTO, 2014, p. 113) Nessa perspectiva, empenhamos nossos esforços no sentido de enxergar os docentes indígenas como interlocutores dos debates em campo e pretendemos compartilhar as reflexões geradas a partir deles, motivando novas discussões em etapas posteriores da pesquisa. Por esses motivos, optamos pela identificação de autoria, consentida pelos sujeitos participantes, tendo em vista nosso interesse em destacar a produção intelectual indígena no que diz respeito às concepções sobre língua, como forma de marcar as ideologias de linguagem geo e corpo-politicamente e provocar a diversificação das epistemologias dentro dos estudos linguísticos.

\section{PRÁTICAS DE BI/PLURI/TRANSLINGUAJAMENTO E METADISCURSOS DE DOCENTES INDÍGENAS: O HIBRIDISMO COMO EPISTEMOLOGIA}

Considerando as concepções de bi/pluri/translinguajamento propostas e discutidas nas seções anteriores, trazemos aqui descrições de duas práticas de translinguajamento ocorridas em contexto de sala de aula da turma de "Português como primeira e segunda 
língua", tema em que estavam presentes estudantes das etnias Guajajara (um docente), Javaé (um docente), Karajá (dois docentes) e Krikati (dois docentes), além do professor responsável e da pesquisadora (que assinam este artigo em coautoria). Enfatizamos que os contextos das interações serão descritos com base nos áudios e vídeos gravados e nas anotações de campo, mas que as falas não serão transcritas tendo em vista as limitações dos pesquisadores, que desconhecem os recursos das línguas indígenas. A intenção é problematizar as práticas comunicativas híbridas de linguagem, mesmo que o conteúdo da interação não possa ser plenamente compreendido, a fim de opô-las às ideologias de linguagem essencialistas e artefatuais, relacionadas a purismo, fixidez e monolinguismo, sempre retomando a necessidade de encarar essa hibridez não só como prática, mas como forma de conceber as línguas, bem como um importante recurso pedagógico em salas multiculturais e plurilíngues.

A primeira situação de interação que será descrita pôde ser observada quase no fim do tempo destinado à realização de uma atividade escrita pelos estudantes, baseada em um roteiro de perguntas que propunha uma reflexão sobre as categorias de linguagem em contextos interculturais. É importante ressaltar que as questões sugeridas tinham o propósito de provocar uma reflexão a partir do conhecimento de cada estudante indígena, sem o intuito de realizar uma avaliação de aprendizagem prévia. Mozart Krikati e Pedro Krikati trabalhavam em dupla para responder as perguntas e, em dado momento, iniciaram uma interação na língua krikati em que puderam ser ouvidas as expressões em português "primeira língua" e "segunda língua", constantes a partir das questões 8 e 9 do roteiro: "O que significa 'primeira língua'?" e "O que significa 'segunda língua'?", respectivamente. Após quase dois minutos de diálogo com utilização majoritária de recursos do krikati, Pedro Krikati passa a elaborar alguns enunciados em língua portuguesa:

[...] aí é segunda língua, mas oralmente não / mas quando a gente escreve se torna primeira. [...] [continuação da interação com uso de recursos da língua krikati] ${ }^{2}$

Há muitas passagens intercaladas em língua portuguesa e em língua indígena. Mozart Krikati predominantemente utiliza os recursos da língua krikati, enquanto Pedro Krikati insere mais enunciados em língua portuguesa. Ao perceber que o professor observa sua conversa com o colega, por exemplo, explica - em um exercício que podemos considerar, ao mesmo tempo, como metalinguístico (porque se refere ao próprio ato de fala) e metapragmático (porque pondera sobre usos linguísticos):

Nós estamos usando aqui a língua / oralmente, né, professor / e isso reforça que é oralmente, né / nossa língua é a primeira / agora escrita / como nós estamos fazendo aqui escrita, é português, né / né, professor

\footnotetext{
${ }^{2}$ Os trechos entre colchetes representam inserções feitas pelos pesquisadores para esclarecer o cotexto/contexto das falas transcritas.
} 
Em uma fala posterior mais detalhada sobre a questão, fica claro que Mozart Krikati e Pedro Krikati defendem a ideia de que a língua krikati é a primeira língua de seu povo na modalidade oral, enquanto a língua portuguesa é a primeira língua de seu povo na modalidade escrita, uma vez que é aprendida na escola antes do ensino da escrita em língua indígena. Essa situação ilustra bem como o contexto de imposição da escrita e as ideologias grafocêntricas são evidenciadas nas práticas e nos metadiscursos e se relacionam mais estritamente com o português - a língua-referência desse mundo da escrita, com o qual os povos indígenas tiveram e têm contato sobretudo por meio da escola. Além disso, mostra como práticas orais e escritas nem sempre são convergentes em situações de bi/pluri/translinguajamento. Aqui, essas modalidades são vistas como partes separadas das línguas, de modo que a "alfabetização" em língua indígena krikati é estritamente ligada à oralidade, enquanto o português parece ser "adquirido" em sua forma escrita, a priori.

A segunda situação aqui descrita como prática de translinguajamento foi observada no último dia do tema contextual, ocasião em que os estudantes iniciaram, a pedido do professor responsável, a elaboração de um plano de aula para ensino de práticas comunicativas em português nas escolas indígenas, a partir de uma discussão anterior sobre a experiência de estágio de um professor indígena Karajá e de uma espécie de roteiro que orientava sobre os pontos mais importantes que deveriam constar no planejamento. Foi disponibilizado um tempo para que os estudantes fizessem a atividade por escrito e, em um segundo momento, eles apresentaram suas propostas.

Durante as apresentações, Tebutxiwe Karajá demonstrou um pouco de dificuldade na compreensão da atividade e apresentou um planejamento que envolvia o ensino de língua indígena, não de português. Após o retorno do intervalo do lanche, ele se direcionou ao professor responsável para tirar dúvidas sobre o plano de aula que tinha elaborado, e Mawisy Karajá também estava acompanhando a discussão. Enquanto esse grupo interagia, os demais estudantes conversavam paralelamente, pois ainda não havia sido iniciado o segundo momento do encontro. Após algumas tentativas de explicação por parte do professor responsável, Mawisy Karajá passou a se dirigir a Tebutxiwe Karajá usando recursos da língua iny, momento em que puderam ser identificadas algumas expressões em língua portuguesa, como "pesquisa" e "assunto". Em uma fala que intercalava língua indígena e língua portuguesa, Mawisy Karajá explica a atividade ao colega:

[uso de recursos da língua iny] [...] identificou um dos problemas da... / identificou um problema, situações [...] [uso de recursos da língua iny] dentro dos gêneros textuais, acho que é interessante ele ter noções / é... / sobre quais são [...] as funções [...]

[uso de recursos da língua iny] [...] meu exemplo / hábito alimentar [...] [uso de recursos da língua iny]

A partir desse momento, Tebutxiwe e Mawisy interagem com utilização predominante de recursos da língua iny, sem a interferência do professor responsável, mas ainda é possível identificar o uso de alguns recursos do português de forma mais isolada: "outro tipo de", "língua portuguesa", "por meio de cartazes". Tebutxiwe conclui 
a interação dizendo que entendeu o que deveria ser feito e o professor responsável disse que leria seu trabalho e lhe daria um retorno posterior sobre a atividade.

As interações descritas são bastante úteis para pensarmos nas funções das práticas de bi/pluri/translinguajamento - que nesse caso se constituem na mobilização de vários recursos considerados como pertencentes a línguas distintas para atender a uma necessidade específica de comunicação, mas não somente isso. Essas práticas nos fazem pensar de forma mais ampla nas negociações linguísticas que ocorrem nessas circunstâncias, com uma mobilização de repertórios que acabam borrando as fronteiras entre as línguas, o que evidencia uma concepção de linguagem que "ultrapassa a pureza monotópica das línguas" (MIGNOLO, 2003, p. 331) e, portanto, desafia as ideologias modernas/coloniais ao usar a língua hegemônica a partir da perspectiva do subalterno, como uma forma de translinguajamento, de "pensar entre línguas".

Os momentos de interação nesse contexto de sala de aula são marcados por práticas comunicativas híbridas também se considerarmos que os estudantes muitas vezes usam os recursos das línguas indígenas de que são falantes para dialogar com seus colegas que compartilham em alguma medida desses recursos, ao mesmo tempo em que usam os recursos da língua portuguesa em outros momentos - ao se dirigirem aos colegas, de modo geral, ao professor responsável pelo tema e à pesquisadora -, reafirmando o lugar do português como uma língua de relações interculturais. Após o início de uma discussão estimulada pelo professor responsável sobre a experiência dos estudantes como docentes nas respectivas aldeias, Paulo Karajá destaca duas situações de uso da língua portuguesa para os povos indígenas:

[...] uma negativa e uma positiva / a negativa é que tem vez que a língua portuguesa entra com a força pra eliminar a nossa palavra / a positiva é que tem vez que essa língua portuguesa ajudou muito a minha comunidade e eu também [...] essa língua portuguesa é muito importante porque quando a gente, por exemplo, eu e o Pedro [Krikati], a gente não conhece nossa língua entre si / através do português eu converso com ele de boa / ele entende o que eu falo e eu entendo o que ele fala [...]

O uso da língua portuguesa, nesse contexto, tem a função (positiva, conforme destaca Paulo Karajá) de promover relações interculturais entre os próprios povos indígenas de etnias distintas. No mesmo sentido se manifesta Mawisy Karajá em atividade escrita, ao responder especificamente à pergunta que questionava sobre as circunstâncias em que a língua portuguesa se mistura com as línguas indígenas nas diferentes situações comunicativas em contextos interculturais:

A mistura da língua portuguesa com a língua indígena tem funções significantes, mas isso depende de seu contexto de uso e de vivência. Um exemplo: Iny não entende nada de língua portuguesa, outro Iny que compreende atua como tradutor, nesse ponto [é] positivo. A mistura não é boa, mas ajuda na comunicação. Um exemplo: uma Iny mestiça [que] entende um pouco a língua iny, quando não consegue se expressar, ela mistura a iny rybè com a língua portuguesa. Nesse sentido é positivo, facilita o aprendizado para ela. 
Por outro lado, na fala de Paulo Karajá transcrita anteriormente pode-se perceber uma preocupação com o processo de "eliminação" da língua que pode ser impulsionado pelo uso do português em situação de contato com as línguas indígenas. Essa também é uma preocupação explicitada na fala de Tebutxiwe Karajá, durante uma discussão anterior que debatia o ensino de português nas escolas indígenas:

[existe] um risco de perder nossa língua / não sei, é preocupação / Gilmar, a mulher que trabalha na educação indígena, ela disse que as crianças estão usando muita língua portuguesa / na escola a gente ensina e orienta para não perder [a língua indígena] / a gente tá aprendendo, eu acho / jovens não têm medo de errar, estão aprendendo [a língua indígena] como primeira língua / mas estão se expressando, utilizando a primeira língua.

Nesses metadiscursos, evidenciam-se alguns índices que apontam para uma ideologia monolíngue e artefatual: os docentes indígenas consideram que, em alguns casos, a língua portuguesa pode se apresentar como uma "ameaça" à língua indígena, pode eliminá-la (Paulo Karajá); ou que há o risco de perda linguística (Tebutxiwe Karajá). Isso retoma a ideia de prefiguração identitária discutida nas seções anteriores, ao passo que representa uma ideologia de diferenciação (língua portuguesa em oposição à língua indígena, "nossa palavra"). Mas é preciso compreender como essas concepções modernas são apropriadas e reelaboradas pelos indígenas nesse caso. É necessário, antes de tudo, situar esses metadiscursos no contexto político e sociolinguístico mais amplo em que estão inseridos os povos indígenas no Brasil, historicamente subjugados e cuja identidade é constantemente questionada com base na (in)existência de uma língua indígena respectiva que componha o imaginário sobre o que é ser índio.

Assim, não se pode ignorar o agenciamento desses sujeitos quando tomam para si uma ideologia de linguagem originalmente essencialista e moderna (monolinguismo/prefiguração identitária) e a reelaboram, apropriando-se dela politicamente, de forma estratégica, para defender seus direitos, negados repetidamente ao longo do tempo com base na utilização dessas mesmas ideologias. Dessa forma, a noção de língua materna como parte da identidade indígena é "desinvestida de seu status idilicamente fetichizado e totalitário" e "passa por profunda revisão em direção à relacionalidade e à contingência contextual” (NASCIMENTO, 2014, p. 118), no que pode ser considerada uma ação orientada para a adoção de um "essencialismo estratégico". Assim como a língua do opressor é reelaborada e usada contra ele próprio (hooks, 2008), as ideologias de linguagem modernas/coloniais também são reconfiguradas, de forma que "as práticas discursivas do colonizador adotadas pelas sociedades indígenas passam por um contínuo de imposição, necessidade, apropriação e resistência" (OLIVEIRA; PINTO, 2011, p. 311).

Por refletirem a condição fronteiriça dos corpos e conhecimentos dos sujeitos indígenas, as práticas e os metadiscursos aqui analisados podem ser percebidos como contraditórios e contingenciais, inseridos em um contínuo cujos polos se constituem na reprodução de ideologias modernas/coloniais de linguagem e ideologias decoloniais. Essas situações trazem à tona a noção de translinguajamento por nós defendida neste artigo, a partir de pressupostos teóricos do campo dos estudos decoloniais, sobretudo 
com fundamento no que postula Mignolo (2003). O hibridismo nas interações comunicativas dos docentes indígenas deve ser pensado não só como prática, mas como epistemologia; como uma alternativa para problematizar os essencialismos decorrentes da invenção das línguas (MAKONI; PENNYCOOK, 2007), em uma tentativa de desinventá-las e reconstituí-las, uma vez que desafiam concepções fixas e totalizantes sobre linguagem, sobretudo em situações em que a complexidade social reconfigura os mapas linguísticos (MIGNOLO, 2003) e exige novas perspectivas, como é o caso dos povos indígenas no Brasil.

"Pensar entre línguas", conforme sugere Mignolo (2003), é provocar uma descentralização epistemológica a partir do espaço da diferença colonial, uma vez que o translinguajamento pode ser visto como uma estratégia de negociação nas relações interculturais, intrinsicamente constituídas na fluidez e no hibridismo, no tetsualü (MEHINAKU, 2010), fundamentadas na mobilização de recursos pertencentes a repertórios linguísticos diversos, móveis e heterogêneos, o que naturalmente desestabiliza as ideologias monotópicas e monolíngues inseridas no imaginário do mundo moderno/colonial (MIGNOLO, 2003).

\section{REFERÊNCIAS}

BLOMMAERT, J. Contexto é/como crítica. Tradução de Daniel do Nascimento e Silva e Clara Dornelles. In: SIGNORINI, I. Situar a linguagem. São Paulo: Parábola, 2008. p. 91115.

BLOMMAERT, J. Discourse. Cambridge: Cambridge University Press, 2005.

BLOMMAERT, J. Ideologias linguísticas e poder. Tradução de Ive Brunelli. In: SILVA, D. do N.; FERREIRA, D. M.; ALENCAR, C. N. (Org.). Nova pragmática: modos de fazer. São Paulo: Cortez, 2014. p. 67-77.

DUSSEL, Enrique. 1492: El encubrimiento del otro: hacia el origen del mito de la modernidad. La Paz: Plural Editores/UMSA. Facultad de Humanidades y Ciencias de la Educación Plural Editores, 1994.

GARCEZ, P. M. Transcrição como teoria: a identificação dos falantes como atividade analítica plena. In: MOITA LOPES, L. P. da; BASTOS, L. C. (Org.). Identidades: recortes multi e interdisciplinares. Campinas: Mercado de Letras, 2002. p. 83-95.

GARCÍA, O.; LI WEI. Translanguaging: language, bilingualism and education. Basingstoke: Palgrave Macmillan, 2014.

HOOKS, bell. Linguagem: ensinar novas paisagens. Estudos feministas, Florianópolis, n. 16, v. 3, p. 857-864, set./dez. 2008.

MEHINAKU, Mutua. Tetsualï: pluralismo de línguas e pessoas no Alto Xingu. 2010. 221 f. Dissertação (Mestrado em Antropologia Social)-Universidade do Rio de Janeiro. Rio de Janeiro, 2010. 
MAKONI, S.; PENNYCOOK, A. Disinventing and reconstituting languages. In: MAKONI, S.; PENNYCOOK, A. (Ed.) Disinventing and reconstituting languages. Clevedon/Buffalo/Toronto: Multilingual Matters, 2007. p. 1-41.

MIGNOLO, W. D. Histórias locais / Projetos globais: colonialidade, saberes subalternos e pensamento liminar. Tradução de Solange Ribeiro de Oliveira. Belo Horizonte: Editora da UFMG, 2003.

NASCIMENTO, A. M. Apontamentos críticos sobre concepções de linguagem na formação superior de docentes indígenas: diálogo intercultural como diálogo interepistêmico. Revista Muitas Vozes, Ponta Grossa, v. 3, n. 1, p. 103-123, 2014.

NASCIMENTO, A. M. Plurilinguismos indígenas no mundo globalizado. Organon, v.32, n.62, p.1-19, 2017.

OLIVEIRA, E. A.; PINTO, J. P. Linguajamentos e contra-hegemonias epistêmicas sobre linguagem em produções escritas indígenas. Linguagem em (Dis)curso, Tubarão, SC, v. 11, n. 2, p. 311-335, maio/ago. 2011.

QUIJANO, A. Colonialidad y modernidad/racionalidad. Perú Indígena, v. 13, n. 29, p. 11 20, 1992.

QUIJANO, A. Colonialidade do poder, eurocentrismo e América Latina. In: LANDER, E. (Org.). A colonialidade do saber: eurocentrismo e ciências sociais. Perspectivas latinoamericanas. Buenos Aires: CLACSO, 2005. p. 227-278.

SIGNORINI, I. Metapragmáticas da língua em uso: unidades e níveis de análise. In: SIGNORINI, I. Situar a linguagem. São Paulo: Parábola, 2008. p. 117-148.

UFG. UNIVERSIDADE FEDERAL DE GOIÁS. Projeto político-pedagógico da Licenciatura Intercultural da Universidade Federal de Goiás. Goiânia, Núcleo Takinahakỹ de formação superior indígena, 2006.

WANG, X. et al. Globalization in the margins: toward a reevolution of language and mobility. Applied Linguistics Review, v. 5, n.1, p. 23-44, 2014. 